\title{
Survey and Research on Continuing Education Curriculum Construction for Primary and Secondary School Teachers
}

\author{
Chao Yang ${ }^{1}$ and Mingjiu $\mathrm{Yu}^{2}$ \\ ${ }^{1}$ Institute of Higher Education and Regional Development, Yunnan Normal University, 650500 Kunming Yunnan, China \\ ${ }^{2}$ Yunnan Normal University, 650500 Kunming Yunnan, China
}

\begin{abstract}
Continuing education curriculum construction is the key work to complete the teachers' continuing education system, it is also an important part of the teachers' specialization. This study aims to master the main problems of the current primary and secondary school teachers' continuing education curriculum construction and put forward the corresponding improvement countermeasures. Research in Yunnan province of China as a case, through the Questionnaire Method, Interview Method and Factors Analysis Method, this study make an thorough analysis on the prominent questions of the curriculum resources informationization level, curriculum structure, curriculum practicability, curriculum management and curriculum evaluation mechanism of the primary and secondary school teachers continuing education curriculums construction. Study found that the curriculum construction should also increase the intensity of curriculum resources informatization, develop diversified curriculum resources, complete six modules, carry out a standardized and scientific management and diversified curriculum evaluation mechanism. Research data and conclusions both enrich the theory of the construction of the teachers continuing education curriculum, and also provide a practical reference for the administrative department of education and teacher training institutions to formulate measures.
\end{abstract}

Keywords. primary and secondary school teachers; continuing education curriculums; curriculum construction

\section{The research design}

\subsection{Research purpose}

This research not only needs to examine the curriculums which have already opened, there is more need to make investigations like testing the degree of satisfaction and demand of the trained teachers towards the curriculums through scientific scale. Therefore, on the basis of the examination of the curriculums which have already opened, after three times adjustment and modification of the questionnaire which lead to a better understand of the satisfaction and demand for the curriculums of the primary and secondary school front-line teachers, this study laid a solid foundation of theory and practice for the construction of the primary and secondary school teachers' continuing education curriculum system in Yunnan province.

\subsection{Research respondents}

In order to ensure the sample representativeness and comprehensiveness of survey data and credibility, the study selected objects from each city, county, town and countryside in Yunnan province who are all in-service primary and secondary school teachers. This study gave out 200 questionnaires, 185 questionnaires had taken back, among them 180 are effective. Effective questionnaire recovery rate is $90 \%$; In addition, this research also chose the managerial personnel from teacher training institutions or schools as respondents of the questionnaire and interview survey. 100 questionnaires were handed out to the managerial personnel, a total of 85 valid questionnaires were taken back, and effective questionnaire recovery rate is $85 \%$. Basic information is detailed in table 1 and table 2 .

Table 1. The teacher sample statistics.

\begin{tabular}{lllll}
\hline & & Frequency(Number) & Percentage(\%) & Cumulative Percentages(\%) \\
\hline \multirow{2}{*}{ Gender } & Male & 78 & 43.3 & 43.3 \\
& Female & 102 & 56.7 & 100 \\
\hline
\end{tabular}

This is an Open Access article distributed under the terms of the Creative Commons Attribution License 4.0, which permits unrestricted use, distribution, and reproduction in any medium, provided the original work is properly cited. 


\begin{tabular}{lllll}
\hline \multirow{5}{*}{ Teaching age } & 5-10years & 76 & 42.2 & 42.2 \\
& 11-15years & 69 & 38.3 & 80.5 \\
& 16-20years & 26 & 14.4 & 94.9 \\
& Over 21years & 9 & 5.1 & 100 \\
\hline \multirow{5}{*}{ Office area } & Cities & 42 & 23.3 & 23.3 \\
& Counties & 81 & 45.0 & 68.3 \\
& (county-level cities) & & 31.7 & 100 \\
\hline
\end{tabular}

Table 2. Managerial personnel sample statistics.

\begin{tabular}{lllll}
\hline & & Frequency (Number) & Percentage(\%) & Cumulative Percentages(\%) \\
\hline \multirow{2}{*}{ Gender } & Male & 46 & 54.1 & 54.1 \\
& Female & 39 & 45.9 & 100 \\
\hline \multirow{6}{*}{ Working age } & 5-9years & 10 & 11.8 & 11.8 \\
& $10-15$ yeas & 20 & 23.5 & 35.3 \\
& 16-20yeas & 22 & 25.9 & 61.2 \\
& 21-25yeas & 14 & 16.5 & 77.7 \\
& 26-30yeas & 12 & 14.1 & 91.8 \\
& 31-35yeas & 7 & 8.2 & 100 \\
\hline
\end{tabular}

\subsection{Research contents and methods}

The research investigate and analysis the curriculum concept, curriculum resources, curriculum type and hierarchy, the informatization level of curriculum construction, practicability, curriculum management and curriculum evaluation and so on. Before the formal investigation, by carried on the forecast of some teachers, took reasonable advises from education experts, instructors and frontline teachers, the outline of Questionnaire and Interview had been modified and improved.

\section{The status survey and problem analy- sis}

\subsection{The difference between curriculum and cur- riculum resources}

This survey found out that in terms of teachers, there are $12.2 \%$ of them can tell the difference between curriculum and curriculum resources, $65.6 \%$ think that there is difference between curriculum and curriculum resources but can not tell the detailed differences, $22.2 \%$ think that there is no difference between the curriculum and curriculum resources. Besides, the survey also detected that, as the growth of the teachers' teaching experience, the proportion of teachers who "can tell the accuracy curriculum concept" is growing, while the proportion of teachers who can't tell the differences or consider there is no difference between them is shrinking. But overall, teachers who are able to recognize the difference still account for a small part. In terms of the managerial personnel, there are $29.4 \%$ of them can tell the difference between curriculum and curriculum resources, $60 \%$ think that there is difference between them but can not tell the detailed differences, $10.6 \%$ think that there is no difference between the curriculum and curriculum resources but only a concept. Furthermore, as the growth of the working age, the proportion of managerial personnel who can tell the difference between curriculum and curriculum resources is growing, while the proportion of managerial personnel who can't tell the differences or consider there is no difference between them is shrinking.

\subsection{The structure of the curriculum}

Look from the aspect of curriculum hierarchy, in terms of moral education class module, $40 \%$ of the total curriculums are recommended by the ministry of education, others accounting for $60 \%$. Among all the established curriculums, $20 \%$ curriculum is repetitively opened, $40 \%$ curriculums are recommended by experts. On the modern education theory and methods module, pedagogy opened a total of 32 curriculums, 23 curriculums are recommended by the ministry of education which accounting for $71 \%$ of the total curriculums pedagogy opened. Besides, there are $21 \%$ curriculums are recommended by experts and $6 \%$ curriculums are recommended by training organizations. $86 \%$ psychology curriculums are recommended by the ministry of education and only $14 \%$ curriculum is recommended by experts. On the modern education technology module, among them $67 \%$ curriculums are recommended by the ministry of education. On the class adviser works module, 33\% curriculums are recommended by the ministry of education, and $50 \%$ curriculums are the same as usual years curriculums, and $17 \%$ curriculums are recommended by experts. On the discipline teaching modules, most are national curriculum while provincial and county level curriculums are very few.

Look from the aspect of curriculum type. First, the humanities and science and technology knowledge module is mostly consist of humanities curriculums, science and technology knowledge curriculums have not been 
adopted. Second, in the aspect of modern education theory and method module, the proportion of subjects is severely imbalanced. Opened curriculums on pedagogy primarily involve the needs in practical teaching. There is no any curriculum which involves the most basic knowledge. This arrangement further weakened the public basic curriculums and professional education curriculums which were already weak in the pre-service education stage. Third, there is no any link between subject curriculum, comprehensive curriculum and interdisciplinary curriculum. The survey found that the specific curriculums that every subject opened are mostly aim at high school physics, without any interdisciplinary curriculums which interact chemical, biological, the geography curriculums.

\subsection{The theoretical property and practicability of curriculum}

The survey found out that curriculum construction showing the characteristic of "disciplinization". Activity curriculums and practical curriculums are not being paid enough attention, theory curriculums and practical curriculums are imbalanced, and the reality of continuing education curriculums can't meet the teachers' expectations. Teachers hold variety expectations occupied a larger proportion in the total respondents while others hold unilateral expectations take a smaller proportion. In the variety aspects of expectations, $25.6 \%$ teachers expect to enhance the teaching ability and solve practical problems, $17.2 \%$ teachers expect to gain new education ideas, methods and knowledge, other aspects only accounted for $6.1 \%$; In unilateral expectations, $12.8 \%$ of the teachers expect to solve the problem of education practice, $10 \%$ for teaching ability, $7.8 \%$ expect to obtain professional knowledge, 5\% expect to gain scientific research ability, $5 \%$ is to fill the school demand and $4.4 \%$ is for the title demand ; In addition, the survey also found that $5 \%$ of teachers think that the training curriculum is strongly practical and can finely guide the teaching practice. $45 \%$ think the practicability is just common and can't obviously guide the teaching practice, $37.8 \%$ think the training curriculum is useless and can't guide the teaching practice. Obviously, teachers' satisfaction on the practicability of current curriculum is low, this isn't consistent with their expectations and also directly reflects the rationality of teachers' continuing education curriculum has to be strengthened.

\subsection{The type of curriculum resources and the level of informatization}

The survey found that $100 \%$ curriculum resources on the two modules of "teacher ethnics" and "class adviser" are from text resources. On the "modern education theory and method" module, 100\% of pedagogy curriculum resources are from the text resources, $86 \%$ of psychology curriculum resources are from the text resources, and the rest $14 \%$ are from multimedia resources. On the "modern education technology and application" module, 83\% curriculum resources are from text resources, $17 \%$ are from multimedia resources; On the "humanities and science and technology knowledge" module, $86 \%$ curriculum resources are from text resources, $14 \%$ are from multimedia resources; On the "Subject teaching" module, $83 \%$ of Chinese, maths and English curriculums are from text resources, $17 \%$ are from multimedia resources; The text resources and multimedia resources are equally accounted $50 \%$ in the subject of science, the multimedia resources in ideology and morality are 100\%. 80\% of history, geography, biology curriculums are from text resources, $20 \%$ are from multimedia resources; $75 \%$ resources of the subject of physics are from text resources, $25 \%$ are from multimedia resources. $83 \%$ resources of the subject of chemistry are from text resources, $17 \%$ are from multimedia resources.

\subsection{The management of curriculum}

The survey found that on the aspect of development and guidance of curriculum, $81.2 \%$ of the managerial personnel think that management organization never invited experts to guide curriculum development, curriculums are only arranged according to the recommendation or appointment by nation and province. On the selectivity of curriculums, elective curriculums are chosen by the management or training institutions while training teachers can only passively accept them, it hasn't put into practice that teachers have the chance to choose curriculums which suit their demands. The survey found that $53.9 \%$ of teachers think it is very necessary to select training curriculums by themselves, $36.1 \%$ of teachers think it is necessary to do that way, the proportion of people who hold the opinion " it doesn't matter" and " not necessary" are respectively $7.2 \%$ and $2.8 \%$. In terms of the supervision of curriculum implementation process, the survey found that the main job of the teachers management or training institutions are statically arrange the curriculum time, select participating experts and teachers and commit their works, there lacks effective means of monitoring for the dynamic process of curriculum implementation. When asking the question of whether they supervised during the curriculum implementation process, $79 \%$ of the managerial personnel said teachers satisfaction on curriculum will be learned through the form of questionnaire and interview during or after class. But very few people suggest to supervise and check the consistency of teaching plan and the actual teaching status and quality.

\subsection{The Curriculum examination and evaluation mechanism}

The survey found out that among the 85 managerial personnel, $29.4 \%$ of them answered curriculum evaluation system has established, $42.4 \%$ of them said " not clear" or "don't know", $28.2 \%$ of them answered there is no specified evaluation system; The second part is the evaluation about the students and their studies. Currently, test results are still the emphasis in the primary and secondary school teachers' continuing education curriculum evaluation, whereas the updating of professional knowledge, the growth of the teaching skills, the cultivation of the spirit 
of unity and cooperation and the progress of ideological quality are neglected. This unilateral way of curriculum evaluation seriously affects the direction and quality of teachers' continuing education. The survey spotted that curriculum evaluation still mostly remain in the final question paper examination, homework assessment and attendance assessment, ways like evaluation of learning process, students' self-evaluation and group evaluation are lacked. During the survey we found that $85.9 \%$ of the managerial personnel agree to take "final question paper examination + attendance+ homework assessment" as the final evaluation form, with $14.1 \%$ of them did not make a clear answer. The "final question paper examination+attendance+homework assessment" evaluation form is consistent with the answer of training teachers.

\section{The main conclusions and recommen- dations}

\subsection{Improve the six curriculum modules}

Teachers' ethics training curriculum module should strengthen teachers' necessary sense of responsibility and mission; enhance the required psychological quality and psychological adjustment ability. Discipline-teaching curriculum module should help teachers constantly grasp and update the advanced teaching idea, add new discipline knowledge, promote problem -solving and researching ability. Modern education theories and methods module help teachers to absorb the latest education research, update the education teaching idea, understand and grasp the new basic education teaching method, promote the ability of combining theory and practice. The modern education technology module should help teachers to understand and grasp the basic modern information technology, constantly increase the consciousness and ability to use modern information technology to carry out teaching. The class adviser's work module is mainly to help teachers improve problem analysis and solving ability. Humanities and science and technology knowledge module not only need to help teachers expand the knowledge of humanities and social science, heighten the humanistic spirit, but also need to help teachers extend knowledge of natural science and technology, strengthen the scientific spirit, master the necessary scientific method.

\subsection{Develop diversified curriculum resources}

First, attaches great importance to the content-based curriculum resources construction. The content-based curriculum resources should including: the curriculum resources which can improve the primary and secondary school teachers' professional knowledge and skills, the curriculum resources which concerning science and technology changes lead to the updating of teachers' knowledge and skills, the curriculum resources for improving teachers' teaching ability, and the curriculum resources which can improve teachers' teaching and researching ability, etc. ${ }^{[1]}$ The second is to strengthen the construction of network and media curriculum resources.
On the one hand, need to make sure that the objective education network and media curriculum resources construction are geared to the latest achievements of modern science and technology development, focus on the latest achievements in modern teaching theory and learning theory. On the other hand, measures should be targeted. For the practical needs of learning teachers, the organization form of curriculum resources should aim at the learning characteristics of teachers, the learning method of the curriculum resources should direct at the practical features of teachers' jobs. In addition, the quantity and quality of the Internet and media curriculum resources should meet teachers' needs.

\subsection{Exercise a standard and scientific curriculum management}

First, clearly define the respective duties and tasks of national, provincial and county levels in management, decentralized the curriculum management authority. Provincial and county level should make curriculum plans which suit the local, to organize and examine the implementation plan of school curriculum, to guide the school to implement national and local curriculum, provide services for the implementation and development of school curriculum .In the first place, the middle curriculum plan and annual training plan should be made together by experts, front-line teachers and administrative personnel according to the guiding advises of national and provincial education administrative departments, teachers' demands and suggestions. ${ }^{[2]}$ In the second place, curriculum plan should aim at the whole implemented curriculums, involving the whole process of curriculum development, implementation and evaluation; Second, pay attention to the steps of curriculum development. On the one hand, give teachers enough time to have a clear understanding and make sufficient prepare of curriculum content, teaching methods and strategies. On the other hand, select textbooks recommended by the ministry of education and the provincial level, meanwhile strengthen the communication on materials between normal universities, brother teachers' further education institutions and primary and secondary schools, write some distinctive textbooks, handouts, self-study materials and local teaching material targetedly, to ensure the richness of teachers' continuing education curriculum resources.

\subsection{Carry out diversified curriculum evaluation mechanism}

First is to use diversified ways of evaluation. Curriculum evaluation should consider primary and secondary school teachers learning and psychological characteristics, based on the actual needs of continuing education activities, different dimensions of methods and ways can be adopted while emphasize practicalness. ${ }^{[3]}$ For example, teachers at different stages respectively take different evaluation methods according to the stage of development in the teachers' professional development process. Different ways of evaluation should also be adopted according to the content of teacher's professional development or 
function or purpose. Second, use multi-agent evaluation. The main body of curriculum evaluation should take teachers' further education institutions, teachers, and education scientific research personnel, training teachers and social related personnel as the main body. In reality, through evaluations on the conditions, process and result of curriculum implementation by multi-agent, make a variety of evaluations organically combined, so as to realize the diversification of evaluation subject of teachers' continuing education curriculums.

\section{References}

1. Lan Ye. The Curriculum Reform and Curriculum Evaluation [M]. Beijing: Education Science Press, 200:128.

2. Rong Wen. Teachers continuing education curriculum problem analysis and countermeasures study [J]. Journal of Continuing Education Research, 2011, (2): 8-11

3. Fuwei Hao. On primary and secondary school teachers continuing education curriculum design and evaluation mechanism [J]. China's Adult Education, 2006, (5):25-28. 